\title{
Detoxification in a structured programme is effective for so-called refractory medication- overuse headache
}

\author{
SB Munksgaard ${ }^{*}, \mathrm{~L}$ Bendtsen, RH Jensen \\ From The European Headache and Migraine Trust International Congress \\ London, UK. 20-23 September 2012
}

\section{Introduction}

The strategy regarding whether detoxification for medication overuse headache $(\mathrm{MOH})$ is needed or not has been heavily debated. Patients are often regarded as treatment resistant if they fail one withdrawal attempt. Further, many report a substantial relapse to $\mathrm{MOH}$ within the first year after withdrawal.

\section{Objective}

To evaluate the long-term efficacy of two different treatment programmes for $\mathrm{MOH}$ in so-called treatment-resistant patients.

\section{Methods}

$\mathrm{MOH}$ patients who had previously been unsuccessfully treated by neurologists were enrolled in one of 2 structured detoxification programmes in a tertiary headache centre: A) a one-week withdrawal with restricted analgesics, rescue medications and prophylactics from Day 1 followed by advice of restricted intake of symptomatic medications or B) a 2-month drug-free period and multidisciplinary education in groups and subsequent initiation of restricted symptomatic medication and prophylactics as required. All patients were closely followed up for a year.

\section{Results}

86 of 98 patients completed the 12-month follow-up. Totally, headache frequency was reduced by $39 \%$ $(\mathrm{p}<0.001)$, medication use by $63 \%(\mathrm{p}<0.001)$ and $83 \%$ remained cured of $\mathrm{MOH}$. Headache frequency was reduced with more than $50 \%$ in 42 patients $(49 \%)$ and $52(61 \%)$ reverted to episodic headache, and with no difference between the groups. Patients in programme B used significantly less symptomatic medication: 6.5 days/ 4 weeks compared with 8.7 days $/ 4$ weeks in programme A $(\mathrm{p}=0.02)$, and the $56 \%$ of patients in programme B who needed prophylactic medication was significantly less than the $80 \%$ in programme A ( $\mathrm{p}=0.02)$. Further, programme $B$ required fewer resources from the staff.

\section{Conclusion}

Structured detoxification with close follow-up by a multidisciplinary team for one year is highly effective in patients with previously treatment-resistant $\mathrm{MOH}$. We recommend a multidisciplinary educational programme for patients in groups due to cost-effectiveness and limited use of medication.

Published: 21 February 2013

\section{doi:10.1186/1129-2377-14-S1-P150}

Cite this article as: Munksgaard et al:: Detoxification in a structured programme is effective for so-called refractory medication-overuse headache. The Journal of Headache and Pain 2013 14(Suppl 1):P150. 